\title{
Six-Minute Walk Test Enhanced by Mobile Telemetric Cardiopulmonary Monitoring
}

\author{
Claudia Tueller ${ }^{a} \quad$ Lukas Kern $^{b}$ Andrea Azzolac Florent Baty $^{b}$ Sophie Condrau ${ }^{d}$ \\ Jan Wiegand ${ }^{\mathrm{e}}$ Michael Tamm ${ }^{\mathrm{d}}$ Martin Brutsche ${ }^{\mathrm{b}}$ \\ ${ }^{a}$ Department of Pulmonary Medicine, University Hospital Bern, Bern, ${ }^{b}$ Division of Pulmonary Medicine, Cantonal \\ Hospital St. Gallen, St. Gallen, ' Regional Hospital Lugano, Lugano, d Division of Pulmonary Medicine, University \\ Hospital Basel, Basel, and ${ }^{e}$ Division of Critical Care Medicine, University Hospital Bern, Bern, Switzerland
}

\section{Key Words}

Cardiopulmonary exercise testing $\cdot$ Six-minute walk test $\cdot$ Mobile cardiopulmonary monitoring • Oxygen uptake • Submaximal exercise

\begin{abstract}
Background: The 6-min walk test (6MWT) is frequently used to assess overall cardiopulmonary fitness and to predict outcome, but it yields little diagnostic information. Portable telemetric devices allow performing the 6MWT with realtime cardiopulmonary monitoring. Objectives: The study was designed to analyze feasibility, safety and clinical usefulness of a mobile cardiopulmonary monitoring (MOB)-enhanced 6MWT. Methods: From August 2003 to June 2007, 261 consecutive patients with chronic lung and/or heart disease as well as healthy controls underwent MOB-enhanced 6 MWTs. A subgroup of 33 individuals had the test done with and without cardiopulmonary monitoring on independent days. Results: No test-related adverse events occurred throughout the study. Whether the 6MWT was done without or with cardiopulmonary monitoring $(n=33)$ did not significantly influence the walking distance (WD: $528 \pm 183$ vs. $525 \pm 192$ m; nonsignificant). Fifty-nine percent (155/261) of
\end{abstract}

the patients fulfilled the maximal test criteria. Distinct disease-specific exercise response patterns as well as treatable co-pathologies were observed. The validity of response patterns was better in case of a maximal test. Conclusion: An MOB-enhanced 6MWT is feasible within daily routine and safe in patients with various diseases. It does not negatively affect WD. MOB is a valuable tool to identify factors limiting exercise in patients irrespective of their underlying disease.

Copyright $\odot 2010$ S. Karger AG, Basel

\section{Introduction}

Walking tests have been used for many years to assess overall performance status of patients with different underlying diseases $[1,2]$. The 6-min walk test $(6 \mathrm{MWT})$ has been extensively investigated and correlates well with impairment in activities of daily life [3]. It is currently used as an indicator when to put patients on a lung transplantation list $[4,5]$, for the assessment and follow-up of patients with various pulmonary diseases $[6,7]$ and for the evaluation of functional outcomes after pulmonary endarterectomy [8]. The walking distance (WD) during the $6 \mathrm{MWT}$ correlates with baseline cardiac output and peak

\section{KARGER}

Fax +41613061234 E-Mail karger@karger.ch www.karger.com (c) 2010 S. Karger AG, Basel

0025-7931/10/0805-0410\$26.00/0

Accessible online at:

www.karger.com/res
Prof. Martin Brutsche, MD, PhD

Division of Pulmonary Medicine, Cantonal Hospital St. Gallen

Rorschacherstrasse 95

CH-9007 St. Gallen (Switzerland)

Tel. +41 71494 1006, Fax +41 71494 6118, E-Mail martin.brutsche@ kssg.ch 
oxygen uptake $\left(\mathrm{VO}_{2 \text { peak }}\right)$ during a maximal cardiopulmonary exercise test [9]. In patients with pulmonary arterial hypertension (PAH), advanced heart failure and idiopathic pulmonary fibrosis, the 6MWT helps to predict mortality [10-12]. However, the 6MWT yields only little information about the underlying cause of exercise limitation.

Classic symptom-limited cardiopulmonary exercise testing (CPET) is used to measure exercise capacity in patients with respiratory or cardiac diseases, to monitor treatment response and to investigate unexplained dyspnea $[13,14] . \mathrm{VO}_{2}$ peak is a strong predictor of survival in patients with primary pulmonary hypertension and an indicator for operability of pulmonary patients [15-17]. The symptom-limited CPET requires more resources than the $6 \mathrm{MWT}$, but carries the advantage of providing important information in order to differentiate between a broad variety of underlying diseases.

The combination of a $6 \mathrm{MWT}$ with a real-time telemetric mobile cardiopulmonary monitoring (MOB) potentially adds the diagnostic power of classic CPET to the safe and time-saving procedure of the 6MWT [18]. MOB might be a superior prognostic and follow-up test compared to conventional $6 \mathrm{MWT}$ in patients with various potentially co-existing exercise-limiting diseases. In a previous study, we were able to demonstrate that MOB is feasible and safe in healthy individuals [18]. In this study, we evaluate the feasibility and safety of MOB in clinical routine in a larger cohort of patients with various underlying diseases and different degrees of exercise limitation. In order to exclude an impact of wearing MOB equipment on $\mathrm{WD}$, conventional $6 \mathrm{MWT}$ and $\mathrm{MOB}$ were performed in randomized order on 2 consecutive days.

\section{Patients and Methods}

\section{Study Design}

The study was conducted at the University Hospital Basel, Switzerland. We included 261 consecutive patients referred to our lung function laboratory for a 6MWT between August 2003 and June 2007 to assess the feasibility, safety and diagnostic yield of MOB in clinical routine. Exclusion criteria were inability to walk, conditions preventing the use of a face mask (e.g. an anatomic face anomaly, panic disorder or claustrophobia), need for oxygen supply during walking and any acute coronary event during the previous month. The consistency of WD measured during conventional 6MWT and MOB was validated in a subset of patients in order to assess potential side effects of the MOB equipment. Twenty-one patients scheduled for a 6MWT and 12 healthy controls were recruited. $6 \mathrm{MWT}$ was performed with and without MOB equipment in randomized order on 2 consecutive days. Patients who had not performed a $6 \mathrm{MWT}$ in the previous 6 months and controls had a practice test first. Patients were excluded from the study if they had a resting $\mathrm{S}_{\mathrm{p}} \mathrm{O}_{2}<85 \%$ while breathing room air. Informed consent was obtained from all participants, and the local ethics committee approved the study.

\section{Six-Minute Walk Test}

A 6MWT with pulse oxymetry was performed on an indoor walking course of $30 \mathrm{~m}$ according to the American Thoracic Society (ATS) guidelines [19]. At the end of the test, WD, Borg dyspnea, fatigue level and subjective reasons for exercise limitation were recorded. The $6 \mathrm{MWT}$ was supervised by an experienced lung function technician.

6MWT with MOB Device

The MOB device (Oxycon Mobile ${ }^{\circledR}$; Viasys Healthcare, USA) consists of an ECG-triggered belt (Polar ${ }^{\circledR}$ Electro OY T-61) or a three-lead electrocardiograph to monitor heart rate, an oxygen sensor for the fingertip to monitor transcutaneous oxygen saturation $\left(\mathrm{S}_{\mathrm{p}} \mathrm{O}_{2}\right)$, a facemask with a dead space $<30 \mathrm{ml}$ and a flow sensor to measure breathing frequency and tidal volumes, a sensor unit containing the oxygen-measuring cell and the carbon dioxide analyzer, a data storage unit and a data transfer unit with integrated long-range telemetry, allowing real-time monitoring of the data on a laptop computer. The weight of the portable equipment is $950 \mathrm{~g}$, including belt, battery and mask (fig. 1). In order to estimate the maximal voluntary ventilation, the first step after installation of the MOB device was to measure forced vital capacity and forced expiratory volume in the 1 st $\mathrm{s}\left(\mathrm{FEV}_{1}\right)$. Spirometry was followed by a resting phase until oxygen consumption $\left(\mathrm{VO}_{2}\right)$ and ventilation reached a steady state. The ensuing $6 \mathrm{MWT}$ was performed according to ATS guidelines [19] and followed by a recovery phase of 4-6 min. WD, Borg dyspnea, fatigue level and the subjective reason for limitation were recorded. $\mathrm{MOB}$ was supervised by an experienced lung function technician and a physician.

In order to determine the test intensity during $\mathrm{MOB}$, suggestions made by the ATS for CPET were applied [20]. The effort was considered maximal if either one or more of the following criteria were fulfilled: (1) maximal heart rate $\geq 90 \%$ of predicted; (2) $\mathrm{VO}_{2 \text { peak }}>84 \%$ of predicted, and (3) ventilatory reserve $<11$ liters or $<15 \% . \mathrm{VO}_{2}$ peak was assessed during the last $15 \mathrm{~s}$ of the $6 \mathrm{MWT}$. Minimal $\mathrm{S}_{\mathrm{p}} \mathrm{O}_{2}$ during $\mathrm{MOB}$ was recorded. $\mathrm{VO}_{2}$ instabilities due to discontinuation of the $6 \mathrm{MWT}$ were not analyzed. Lung function parameters were interpreted according to ATS standards. Standard equations were used to calculate ventilatory reserve [1 ( $\mathrm{VE}_{\max } /$ maximal voluntary ventilation)], maximal predicted values for $\mathrm{VO}_{2}[(60-0.55 \times$ age $)$ for males and $(48-0.37 \times$ age $)$ for females] and maximal predicted heart rate $(220$ - age) $[21,22]$.

\section{Statistical Analysis}

Data were analyzed using $\mathrm{R}$ (version 2.9.0). Results are expressed as medians (range) or means $\pm \mathrm{SD}$ as appropriate. Comparisons between different disease categories were done using analysis of variance for parametric variables and $\chi^{2}$ tests for differences between proportions. Spearman's rank correlation was calculated between $\mathrm{VO}_{2}$ and $\mathrm{WD}$. Agreement between conventional and MOB 6-min walk distance (6MWD) was tested using the Bland-Altman and linear regression analysis. Individual response patterns to exercise were analyzed using principal component analysis. Principal component analysis summarizes multivariate information into a small set of orthogonal vectors (principal com- 
Fig. 1. MOB-enhanced 6MWT. The test is performed on an indoor 30-meter track and conducted according to ATS recommendations. The patient is wearing the 950-gram equipment including a face mask.
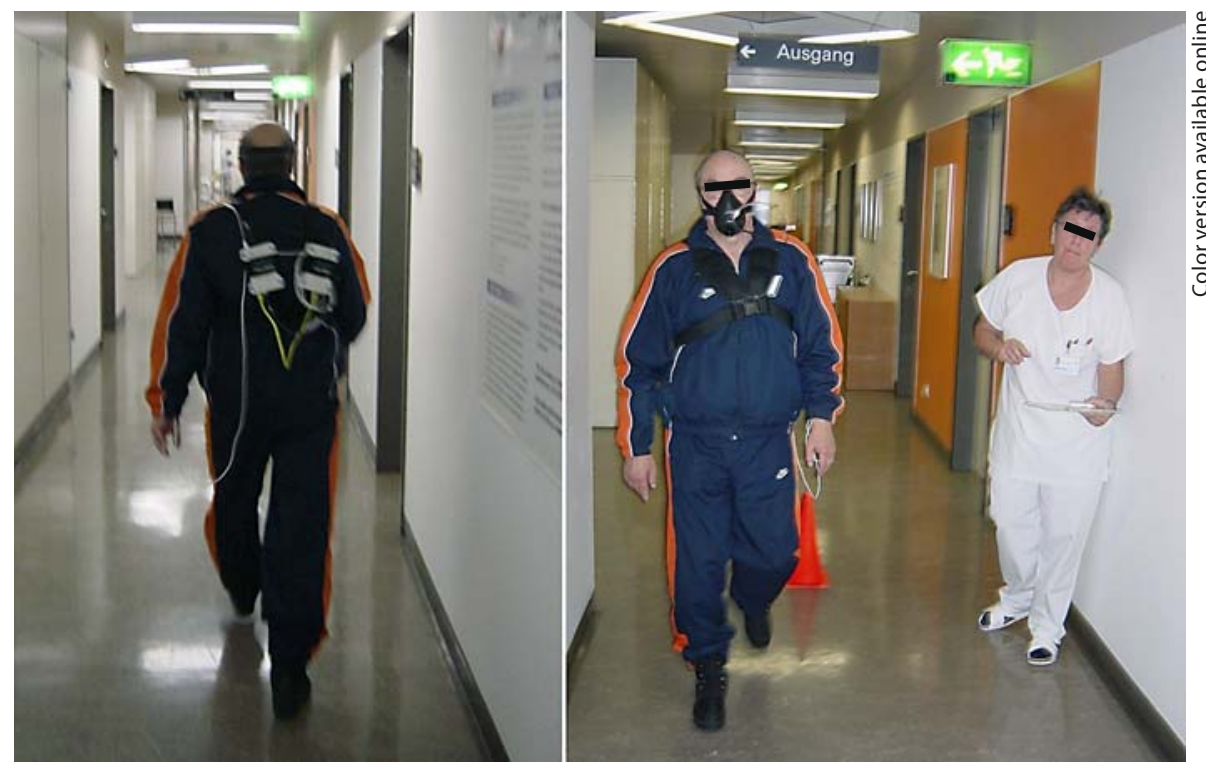

ponents) which extract the main sources of variation present in the dataset. Individual classification of patients into predefined diagnostic categories was assessed by between-group analysis (BGA) [23], a supervised counterpart of the principal component analysis.

\section{Results}

\section{WD of Conventional 6MWT Compared to $M O B$}

Thirty-three individuals (21 patients and 12 healthy controls) performed both 6MWT and MOB on consecutive days in random order (table 1). No significant difference in the WD between 6MWT and MOB was found (mean WD during 6MWT $528 \pm 183 \mathrm{~m}$ vs. mean WD during MOB $525 \pm 192 \mathrm{~m}$; nonsignificant). Sixteen of the 33 participants had a longer WD during 6MWT compared to MOB, 16 performed better during $\mathrm{MOB}$ and 1 individual walked exactly the same distance in both tests. The test order - first $6 \mathrm{MWT}$ or MOB - did not significantly influence WD. Bland-Altman analysis showed good agreement between MOB and conventional WDs with a bias of $3 \mathrm{~m}$ (95\% confidence interval: -6 to 12) and a precision of $26 \mathrm{~m}$ (fig. 2). Regression analysis gave a linear model with a slope of $1.04 \pm 0.02$ and an intercept of $-25.8 \pm 13.3$ and shows an excellent goodness of fit (residual $\mathrm{SE}=24.6, \mathrm{R}^{2}=0.98$; fig. 2 )

\section{Feasibility and Safety of $M O B$}

Two-hundred forty-four patients and 17 controls performed an enhanced 6MWT with MOB. Although 131 of the $244(54 \%)$ patients were severely impaired, with a
Table 1. Demographics and exercise parameters of patients and healthy controls performing both $6 \mathrm{MWT}$ and MOB on separate days in random test order

\begin{tabular}{lcc}
\hline & $\begin{array}{c}\text { Patients } \\
(\mathrm{n}=21)\end{array}$ & $\begin{array}{c}\text { Healthy } \\
\text { controls } \\
(\mathrm{n}=12)\end{array}$ \\
& & $5 / 7$ \\
& $13 / 8$ & $32 \pm 10$ \\
Sex, males/females & $57 \pm 14$ & \\
Age, years & & \\
Disease category, $\mathrm{n}$ & 6 & \\
$\quad$ Restrictive lung disease & 7 & \\
$\quad$ Obstructive lung diseases & 6 & $103 \pm 9$ \\
$\quad$ Pulmonary hypertension & 2 & $732(668-904)$ \\
$\quad$ Cardiac disease & $26.6 \pm 6.5$ & $4.9 \pm 2.1$ \\
Body mass index & $83 \pm 29$ & $4.3 \pm 1.6$ \\
FEV, \% predicted & $420(180-566)$ & $19 \pm 13$ \\
MOB WD, m & $5.1 \pm 2.6$ & $2.5 \pm 1.8$ \\
MOB Borg & $440(219-560)$ \\
6MWT WD, m & $4.2 \pm 2.3$ & \\
6MWT Borg & $23 \pm 15$ & \\
Difference in WD, m & $5.9 \pm 4.6$ & \\
$\quad \%$ of WD &
\end{tabular}

Means $\pm \mathrm{SD}$ and medians (ranges).

baseline $\mathrm{FEV}_{1}<50 \%(\mathrm{n}=54 ; 22 \%)$, a WD $<300 \mathrm{~m}(\mathrm{n}=46$; $19 \%)$ or both ( $\mathrm{n}=28 ; 11 \%)$, no adverse events (syncope, chest pain, arrhythmia, prolonged hypoxemia or bronchospasm) occurred. Technical problems occurred in 11 of 261 (4\%) tests: evaluation of heart rate, $\mathrm{FEV}_{1}$ and saturation were not possible in 4,1 and 6 tests, respectively. 

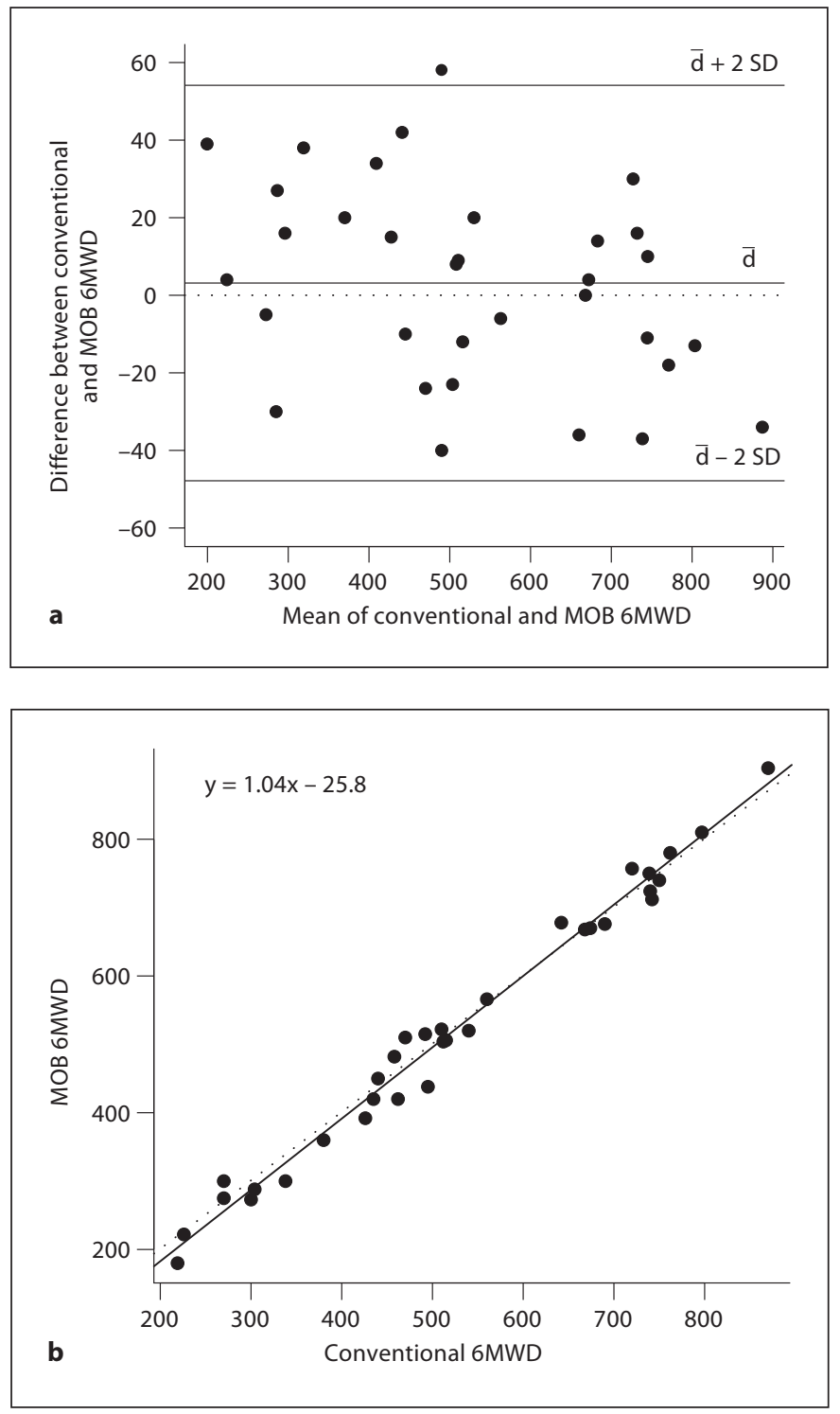

Fig. 2. WD measured during MOB and conventional 6MWT did not differ. a Bland-Altman difference plot. - = systematic bias $(\overline{\mathrm{d}})$ and the limits of agreement $(\overline{\mathrm{d}} \pm 2 \mathrm{SD})$. $\mathbf{b}$ Linear regression plot. Both the line of best fit (-) and the identity line $(\ldots \ldots)$ are displayed.

\section{Diagnostic Yield of $M O B$}

Although $6 \mathrm{MWT}$ is generally considered to be associated with submaximal effort, 155 of the 261 (59\%) MOB tests reached criteria for maximal effort as specified above. Twenty-three (9\%) subjects reached a heart rate $>90 \%$ of the predicted maximal heart rate, 36 (14\%) subjects had $\mathrm{VO}_{2}$ peak $\geq 84 \%$ predicted and 97 (37\%) subjects reached ventilatory limits with either ventilatory reserve
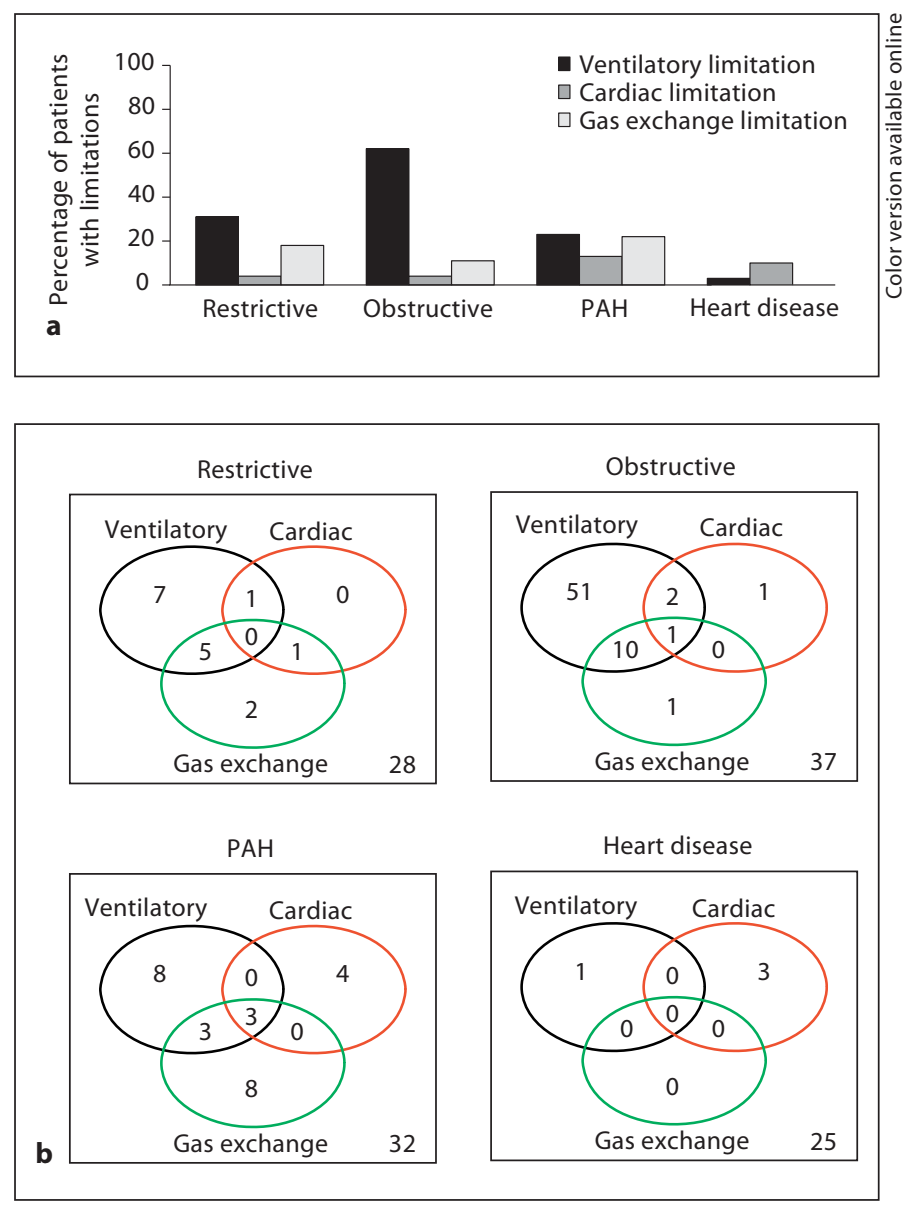

Fig. 3. Observed exercise limitations according to disease categories. The bar plots (a) show the percentage of patients with limitations in each disease category. Exercise limitation did not follow the pretest expectation in all cases, leading to the detection of previously unknown co-morbidities. b Individual details are given in the Venn diagram. The numbers in the lower right corner indicate the number of patients without any limitation.

$<11$ liters or $<15 \%$. Twenty-four of the 155 subjects (15\%) fulfilled more than one criterion for maximal exercise.

The underlying cause of exercise limitation could be identified in 124 (48\%) tests. Eighty-six (33\%) patients had a ventilatory limitation, 27 (10\%) had a cardiocirculatory limitation and $11(4 \%)$ had an isolated decrease in $\mathrm{S}_{\mathrm{p}} \mathrm{O}_{2}<80 \%$. In half of the patients $(\mathrm{n}=38 ; 51 \%)$ with severely impaired $\mathrm{WD}<300 \mathrm{~m}(\mathrm{n}=74)$, the underlying cause of exercise limitation could be identified. In most of the tests, limitation corresponded to the underlying disease (table 2). In several patients, the cause of exercise limitation did not correspond with the underlying disease leading to the identification of potentially treatable 


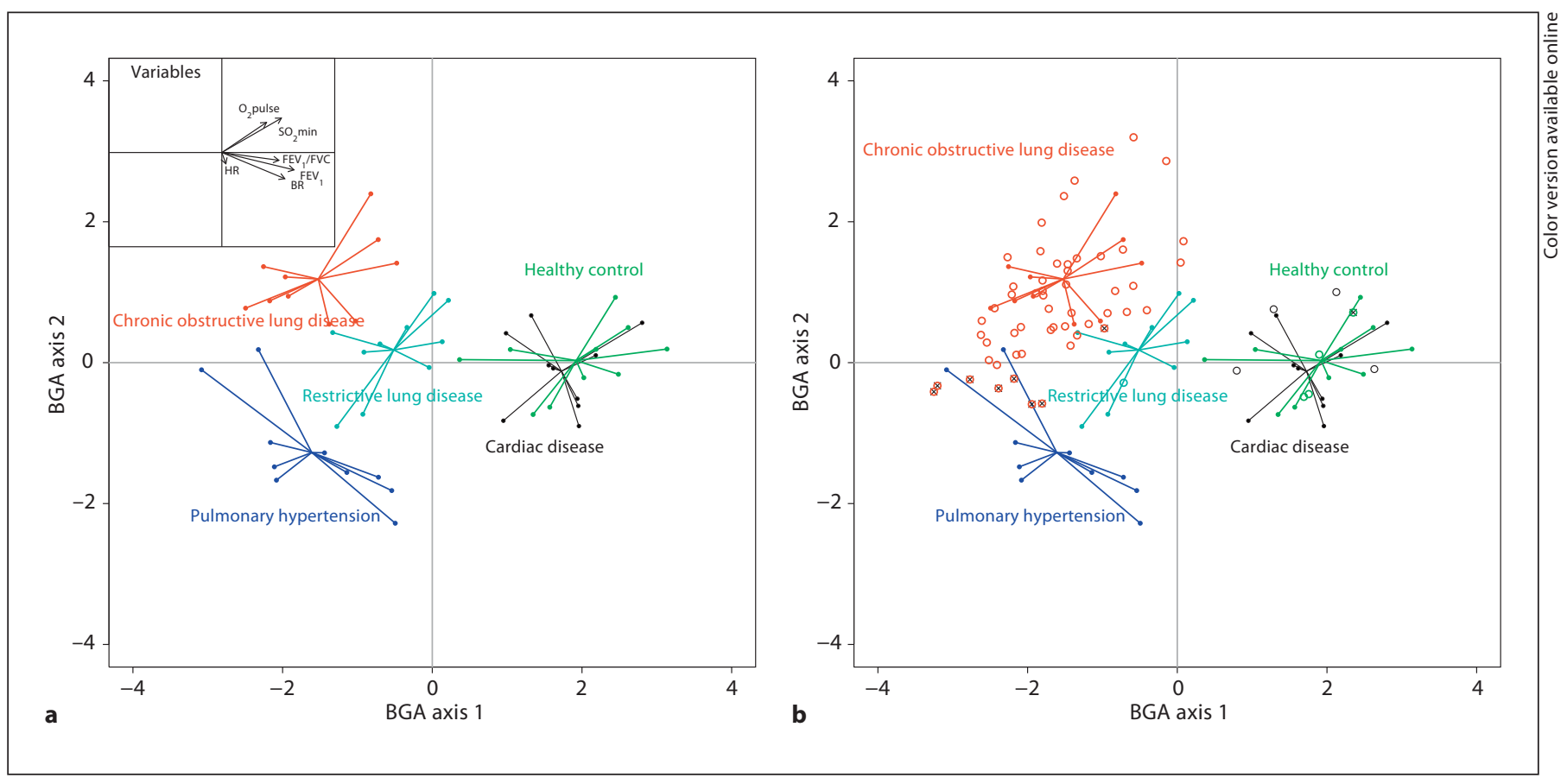

Fig. 4. BGA of individual response patterns to exercise (maximal tests only; $n=50$ ). $\mathbf{a}$ The patients' classification on the first 2 axes of BGA (variables are shown in the upper left quadrant) in the 'training set' of 10 randomly selected patients/individuals per disease group. $\mathbf{b}$ The classification of the rest of the patients that

reached criteria for maximal exercise (empty circles). Crossed circles correspond to patients with a discrepant exercise response pattern potentially unveiling co-pathologies ('test set'). Cardiac patients and healthy controls showed nearly identical response patterns.

co-morbidities. Some patients reached more than one criterion for maximal exercise (fig. 3). The disease-specific profiles of patients are presented in figure 4 . Figure $4 \mathrm{a}$ displays 10 randomly chosen patients with maximal exercise test criteria from each disease group ('training set'). The first BGA axis discriminates healthy controls and cardiac disease patients from the three other groups. Cardiac patients and healthy controls had nearly identical response patterns, being in line with the fact that cardiovascular limitation is physiological. The second BGA axis discriminates between patients with pulmonary hypertension and patients with chronic obstructive pulmonary disease (COPD)/restrictive lung disease. The classification accuracy of the other patients having reached criteria for maximal exercise ('test set') was $85 \%$. Figure $4 \mathrm{~b}$ shows that 9 patients were misclassified, including 7 COPD patients tending to be classified as pulmonary hypertension patients. Overall, WD during $\mathrm{MOB}$ correlated significantly with $\mathrm{VO}_{2}$ peak in the total population $(\mathrm{r}=0.82$, $\mathrm{p}<$ 0.001 ), as well as within the different disease categories. Patients with COPD had a shorter WD for comparable $\mathrm{VO}_{2}$ than other patients (fig. 5).

\section{Discussion}

The results of this study show that the use of a telemetric MOB during a conventional 6MWT is feasible in clinical routine, safe even in severely impaired patients and of higher diagnostic value than the 6MWT alone.

In our study, $\mathrm{MOB}$ equipment and software proved to be reliable. Minor technical problems occurred in only $4 \%$ of the tests and consisted mostly of artifacts in the readings of heart rate or $\mathrm{S}_{\mathrm{p}} \mathrm{O}_{2}$. In most cases, sufficient information for the interpretation of MOB was available. Since pulse oxymetry showed significant desaturation in most patients and even in most healthy controls, $\mathrm{S}_{\mathrm{p}} \mathrm{O}_{2}$ seemed to be of limited value. We were able to show that wearing mobile CPET equipment does not influence the $6 \mathrm{MWD}$, thus enabling the comparison of WD measured by MOB and conventional 6MWT. Importantly, no serious adverse event occurred during MOB. It proved to be as safe as the conventional 6MWT even in severely impaired patients. MOB however is more time consuming than the conventional 6MWT. Overall, it took roughly 30 min for a technician to complete a test, about 10-15 $\mathrm{min}$ 
Table 2. Demographics and exercise responses during MOB (means \pm SD)

\begin{tabular}{|c|c|c|c|c|c|c|}
\hline & Controls & $\begin{array}{l}\text { Restrictive } \\
\text { lung disease } \\
(\mathrm{n}=45)\end{array}$ & $\begin{array}{l}\text { Obstructive } \\
\text { lung disease } \\
(\mathrm{n}=106)\end{array}$ & $\begin{array}{l}\text { PAH } \\
(n=64)\end{array}$ & $\begin{array}{l}\text { Heart disease } \\
(\mathrm{n}=29)\end{array}$ & $\begin{array}{l}\text { All subjects } \\
(\mathrm{n}=261)\end{array}$ \\
\hline Sex, males/females & $9 / 8$ & $23 / 22$ & $61 / 45$ & $24 / 40$ & $17 / 12$ & $127 / 134$ \\
\hline Age, years & $37 \pm 12$ & $62 \pm 12$ & $62 \pm 14$ & $61 \pm 14$ & $70 \pm 9$ & $61 \pm 15$ \\
\hline Body mass index & $24 \pm 4$ & $29 \pm 7$ & $25 \pm 6$ & $27 \pm 6$ & $31 \pm 8$ & $27 \pm 7$ \\
\hline $\mathrm{FEV}_{1}, \%$ predicted $^{\mathrm{a}}$ & $107 \pm 11$ & $72 \pm 22$ & $49 \pm 21$ & $76 \pm 27$ & $92 \pm 23$ & $68 \pm 29$ \\
\hline $\mathrm{VO}_{2}, \mathrm{ml} / \mathrm{kg} / \mathrm{min}$ & $32 \pm 6$ & $15 \pm 3$ & $15 \pm 4$ & $13 \pm 3$ & $14 \pm 3$ & $15 \pm 6$ \\
\hline $\mathrm{VO}_{2 \text { peak }} \%$ predicted $^{\mathrm{a}}$ & $95 \pm 16$ & $66 \pm 19$ & $60 \pm 17$ & $58 \pm 18$ & $66 \pm 14$ & $63 \pm 19$ \\
\hline $\mathrm{n}>84 \%$ & $11(65 \%)$ & $7(16 \%)$ & $11(10 \%)$ & $5(8 \%)$ & $2(7 \%)$ & $36(14 \%)$ \\
\hline $\mathrm{WD}, \mathrm{m}^{\mathrm{a}}$ & $720 \pm 81$ & $389 \pm 106$ & $340 \pm 123$ & $339 \pm 118$ & $348 \pm 94$ & $374 \pm 147$ \\
\hline $\mathrm{n}<300 \mathrm{~m}$ & 0 & $7(16 \%)$ & $33(31 \%)$ & $25(39 \%)$ & $9(31 \%)$ & $74(28 \%)$ \\
\hline Ventilatory reserve, $\%^{\mathrm{a}}$ & $47 \pm 17$ & $31 \pm 19$ & $21 \pm 19$ & $35 \pm 18$ & $48 \pm 14$ & $31 \pm 21$ \\
\hline $\mathrm{n}<15 \%$ or $<11$ liters & $1(6 \%)$ & $14(31 \%)$ & $66(62 \%)$ & $15(23 \%)$ & $1(3 \%)$ & $97(37 \%)$ \\
\hline Maximal heart rate, $\%$ predicted $^{\mathrm{b}}$ & $85 \pm 11$ & $71 \pm 12$ & $69 \pm 13$ & $72 \pm 16$ & $70 \pm 13$ & $71 \pm 14$ \\
\hline $\mathrm{n}>90 \%$ & $6(35 \%)$ & $2(4 \%)$ & $4(4 \%)$ & $8(13 \%)$ & $3(10 \%)$ & $23(9 \%)$ \\
\hline Minimal $\mathrm{S}_{\mathrm{p}} \mathrm{O}_{2}, \%^{\mathrm{c}}$ & $91 \pm 5$ & $87 \pm 7$ & $87 \pm 6$ & $84 \pm 7$ & $92 \pm 3$ & $87 \pm 7$ \\
\hline $\mathrm{n}<80 \%$ & 0 & $8(18 \%)$ & $12(11 \%)$ & $14(22 \%)$ & 0 & $34(13 \%)$ \\
\hline
\end{tabular}

${ }^{\mathrm{a}}$ Missing values, $\mathrm{n}=1$; $^{\mathrm{b}}$ missing values, $\mathrm{n}=4 ;^{\mathrm{c}}$ missing values, $\mathrm{n}=6$.

more than for a conventional 6MWT. Previous studies showed that telemetric measurement of metabolic and ventilatory data is feasible and safe in healthy individuals $[18,21]$. Telemetric systems were used to analyze cardiorespiratory adaptations during 6MWT, and reliability and intensity of the 6MWT in patients with chronic heart failure [24, 25], COPD [26, 27] and PAH [28]. Different authors described a correlation between the 6MWD and $\mathrm{VO}_{2}$ measured during CPET on a cycle ergometer in patients with COPD [29], chronic heart failure and pulmonary hypertension $[9,10]$. In these studies, the correlation coefficient between the $\mathrm{WD}$ and $\mathrm{VO}_{2}$ peak ranged from 0.48 for patients with PAH to 0.73 for patients with COPD. The present study is the first to investigate the correlation between simultaneously measured $\mathrm{WD}$ and $\mathrm{VO}_{2}$ during a 6MWT in a larger cohort of patients with varying underlying diseases. We found a correlation coefficient of 0.82 for the simultaneous measurement of WD and $\mathrm{VO}_{2 \text { peak }}$ during $\mathrm{MOB}$.

6MWT is generally considered to be a submaximal test [21]. However, in our study, 59\% of the participants met the criteria of maximal effort. There are other reports that conclude that the $6 \mathrm{MWT}$ might be a maximal test in patients with heart failure [24] and COPD [30, 31]. Troosters et al. [27] compared the physiological responses to exercise during an encouraged 6MWT and an incre- mental cycle CPET in patients with COPD. A similar $\mathrm{VO}_{2}$ peak was found for both tests, but a $\mathrm{VO}_{2}$ plateau was typically reached after the 3rd min during the 6MWT.

Therefore, the 6MWT is believed to better assess steady-state exercise performance compared to incremental cycle CPET. A plateau of $\mathrm{VO}_{2}$ might better reflect the integrated physiologic response to exercise and, therefore, explain the high prognostic value of the 6MWT.

We observed disease-specific patterns of response to exercise. Patients with pulmonary hypertension had a particularly low $\mathrm{VO}_{2}$ peak and a low $\mathrm{S}_{\mathrm{p}} \mathrm{O}_{2}$, possibly due to the pronounced impairment in diffusion leading to hypoxemia, with increased dead space ventilation due to pulmonary vascular obliteration and an insufficient rise in cardiac output during exercise due to excessively high pulmonary vascular resistance [32]. In contrast, patients with COPD had a relatively high $\mathrm{VO}_{2}$ peak at a similar WD. Probably, the reduced WD in these patients might be explained by the systemic nature of COPD with skeletal muscle involvement $[33,34]$ and/or a more pronounced physical deconditioning.

The present study also demonstrates that $\mathrm{MOB}$ compared to conventional 6MWT leads to additional diagnostic information, such as overall fitness and the cause of exercise limitation irrespective of the underlying dis- 


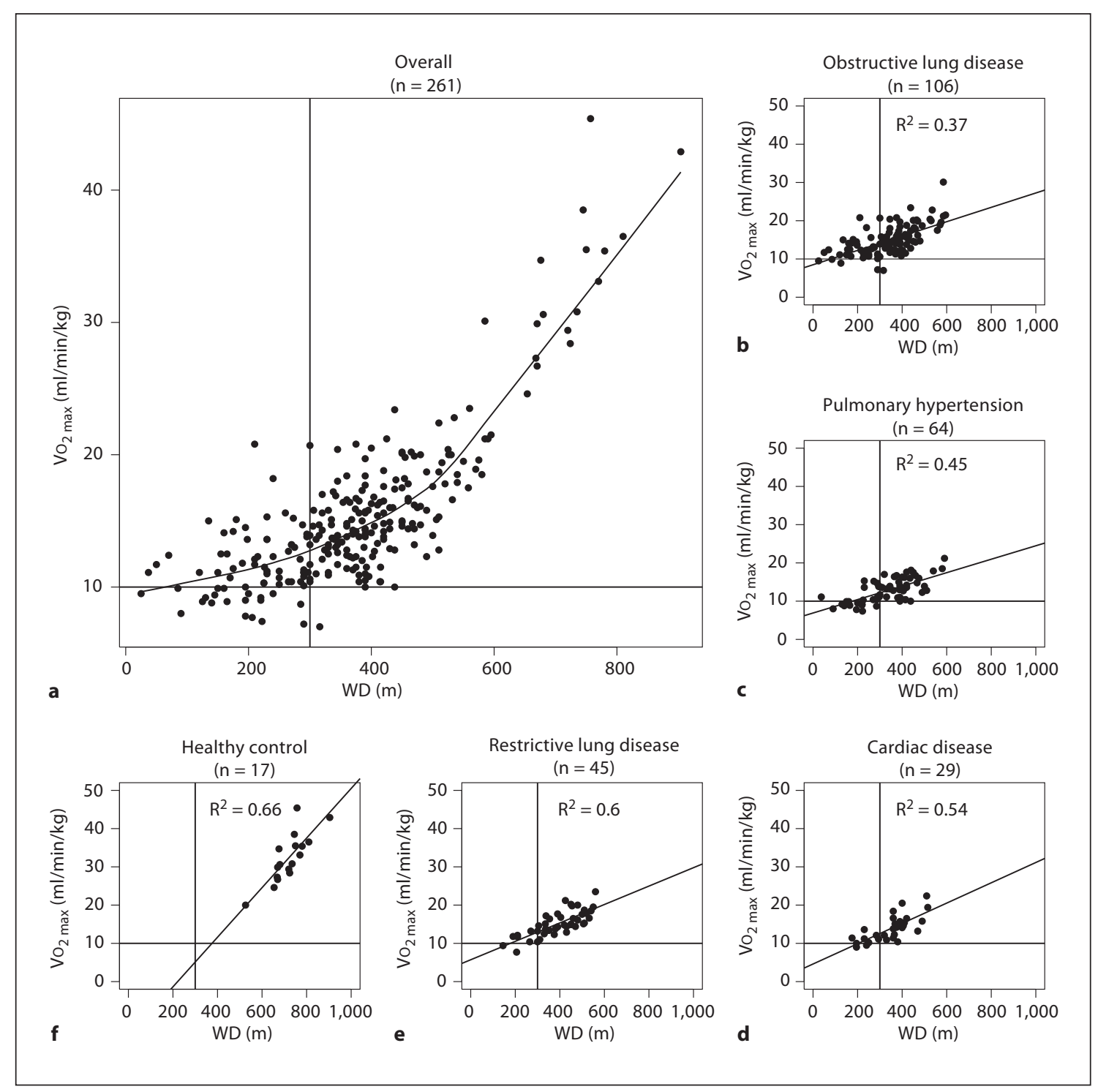

Fig. 5. Correlation between $\mathrm{WD}$ and $\mathrm{VO}_{2}$ peak measured during $\mathrm{MOB}$-enhanced $6 \mathrm{MWT}$ (coefficients of determination, $\mathrm{R}^{2}$ ). Correlations within the total population $(\mathrm{n}=261 ; \mathbf{a})$ and disease-specific categories and healthy controls are shown (b-f).

ease. For example, we could identify cardiac limitation due to exercise-induced arrhythmia in patients with restrictive lung disease or ventilatory limitation in patients with pulmonary vascular disease or chronic heart disease. In these patients, MOB had a significant impact on their management. In addition, as depicted in figure 4 , we could detect COPD patients with potentially underlying/ associated $\mathrm{PAH}$ using $\mathrm{MOB}$, since they showed exercise characteristics of both disease groups. Holverda et al. [35] described a large overlap in exercise test characteristics of
COPD patients with and without associated pulmonary hypertension and concluded that in addition to a low ventilatory efficiency, a low resting $\mathrm{S}_{\mathrm{p}} \mathrm{O}_{2}$ and accentuated decrease during exercise suggest the presence of $\mathrm{PAH}$ in COPD patients.

Further, the WD of a conventional 6MWT might vary due to physiologic changes, but also due to varying compliance of the patient. During MOB, the patients' compliance and exercise quality can be assessed simultaneously by measuring heart rate, ventilatory reserves and $\mathrm{S}_{\mathrm{p}} \mathrm{O}_{2}$ 
during exercise. Comparing exercise intensity of consecutive tests allows a more objective assessment of changes in the response to exercise over time.

In conclusion, we could show that enhancing the $6 \mathrm{MWT}$ by telemetric MOB in patients with varying degree of exercise limitation is safe and clinically useful. The use of mobile CPET equipment did not negatively affect WD. WD during MOB significantly correlated with $\mathrm{VO}_{2}$ peak in both maximal and submaximal tests. MOB gave additional diagnostic and disease-specific information compared to the $6 \mathrm{MWT}$ alone. It could identify the true cause of exercise limitation irrespective of the underlying disease and allowed to assess patients' compliance during exercise. Therefore, in our opinion, MOB-enhanced 6MWT is a promising clinical investigative tool. Further investigations are required to investigate the role of $\mathrm{MOB}$ as a diagnostic and follow-up tool in specific subgroups of patients.

\section{Acknowledgments}

We are indebted to Karl Wasserman, Micha T. Maeder, Michael Koller and Werner Strobel for their critical review of this paper.

\section{References}

1 Lehmann M, Karali F: Walking test before decision on mitral commissurotomy. J Med Lyon 1953;34:675-683.

2 Balke B: A simple field test for the assessment of physical fitness. Rep 63-6. Rep Civ Aeromed Res Inst US 1963, pp 1-8.

-3 Solway S, Brooks D, Lacasse Y, Thomas S: A qualitative systematic overview of the measurement properties of functional walk tests used in the cardiorespiratory domain. Chest 2001;119:256-270.

4 Kadikar A, Maurer J, Kesten S: The six-minute walk test: a guide to assessment for lung transplantation. J Heart Lung Transplant 1997;16:313-319.

5 Lederer DJ, Arcasoy SM, Wilt JS, D’Ovidio F, Sonett JR, Kawut SM: Six-minute-walk distance predicts waiting list survival in idiopathic pulmonary fibrosis. Am J Respir Crit Care Med 2006;174:659-664.

-6 Torbicki A, Kurzyna M: Pulmonary arterial hypertension: evaluation of the newly diagnosed patient. Semin Respir Crit Care Med 2005;26:372-378

7 Baughman RP, Sparkman BK, Lower EE: Sixminute walk test and health status assessment in sarcoidosis. Chest 2007;132:207213.

-8 Reesink HJ, van der Plas MN, Verhey NE, van Steenwijk RP, Kloek JJ, Bresser P: Six-minute walk distance as parameter of functional outcome after pulmonary endarterectomy for chronic thromboembolic pulmonary hypertension. J Thorac Cardiovasc Surg 2007;133:510-516.

-9 Oudiz RJ, Barst RJ, Hansen JE, Sun XG, Garofano R, Wu X, et al: Cardiopulmonary exercise testing and six-minute walk correlations in pulmonary arterial hypertension. Am J Cardiol 2006;97:123-126.
10 Miyamoto S, Nagaya N, Satoh T, Kyotani S, Sakamaki F, Fujita M, et al: Clinical correlates and prognostic significance of six-minute walk test in patients with primary pulmonary hypertension. Comparison with cardiopulmonary exercise testing. Am J Respir Crit Care Med 2000;161:487-492.

11 Paciocco G, Martinez FJ, Bossone E, Pielsticker E, Gillespie B, Rubenfire M: Oxygen desaturation on the six-minute walk test and mortality in untreated primary pulmonary hypertension. Eur Respir J 2001;17:647-652.

$\checkmark 12$ Swigris JJ, Swick J, Wamboldt FS, Sprunger D, du Bois R, Fischer A, et al: Heart rate recovery after 6-min walk test predicts survival in patients with idiopathic pulmonary fibrosis. Chest 2009;136:841-848.

13 Sridhar MK, Carter R, Banham SW, Moran F: An evaluation of integrated cardiopulmonary exercise testing in a pulmonary function laboratory. Scott Med J 1995;40:113116.

14 Palange P, Ward SA, Carlsen KH, Casaburi R, Gallagher CG, Gosselink R, et al: Recommendations on the use of exercise testing in clinical practice. Eur Respir J 2007;29:185209.

15 Wensel R, Opitz CF, Anker SD, Winkler J, Höffken G, Kleber FX, et al: Assessment of survival in patients with primary pulmonary hypertension: importance of cardiopulmonary exercise testing. Circulation 2002;106: 319-324.

16 Brutsche MH, Spiliopoulos A, Bolliger CT, Licker M, Frey JG, Tschopp JM: Exercise capacity and extent of resection as predictors of surgical risk in lung cancer. Eur Respir J 2000;15:828-832.

17 Bolliger CT, Koegelenberg CF, Kendal R: Preoperative assessment for lung cancer surgery. Curr Opin Pulm Med 2005;11:301306.
18 Attinger A, Tueller C, Souren T, Tamm M, Schindler C, Brutsche MH: Feasibility of mobile cardiopulmonary exercise testing. Swiss Med Wkly 2006;136:13-18.

19 ATS statement: guidelines for the six-minute walk test. Am J Respir Crit Care Med 2002; 166:111-117.

20 ATS/ACCP statement on cardiopulmonary exercise testing. Am J Respir Crit Care Med 2003; 167:211-277

21 Kervio G, Carre F, Ville NS: Reliability and intensity of the six-minute walk test in healthy elderly subjects. Med Sci Sports Exerc 2003;35:169-174.

22 Fairbarn MS, Blackie SP, McElvaney NG, Wiggs BR, Paré PD, Pardy RL: Prediction of heart rate and oxygen uptake during incremental and maximal exercise in healthy adults. Chest 1994;105:1365-1369.

23 Baty F, Bihl MP, Perrière G, Culhane AC, Brutsche MH: Optimized between-group classification: a new jackknife-based gene selection procedure for genome-wide expression data. BMC Bioinformatics 2005;6:239.

24 Faggiano P, D’Aloia A, Gualeni A, Giordano A: Assessment of oxygen uptake during the six-minute walk test in patients with heart failure. Chest 1997;111:1146.

25 Riley M, McParland J, Stanford CF, Nicholls DP: Oxygen consumption during corridor walk testing in chronic cardiac failure. Eur Heart J 1992;13:789-793.

26 Probst VS, Troosters T, Coosemans I, Spruit MA, Pitta Fde O, Decramer M, et al: Mechanisms of improvement in exercise capacity using a rollator in patients with COPD. Chest 2004;126:1102-1107.

-27 Troosters T, Vilaro J, Rabinovich R, Casas A, Barberà JA, Rodriguez-Roisin R, et al: Physiological responses to the 6-min walk test in patients with chronic obstructive pulmonary disease. Eur Respir J 2002;20:564-569. 
-28 Deboeck G, Niset G, Vachiery JL, Moraine JJ, Naeije R: Physiological response to the sixminute walk test in pulmonary arterial hypertension. Eur Respir J 2005;26:667-672.

-29 Turner SE, Eastwood PR, Cecins NM, Hillman DR, Jenkins SC: Physiologic responses to incremental and self-paced exercise in COPD: a comparison of three tests. Chest 2004;126:766-773.

- 30 Casas A, Vilaro J, Rabinovich R, Mayer A, Barberà JA, Rodriguez-Roisin R, et al: Encouraged 6-min walking test indicates maximum sustainable exercise in COPD patients. Chest 2005;128:55-61.
31 Onorati P, Antonucci R, Valli G, Berton E, De Marco F, Serra P, et al: Non-invasive evaluation of gas exchange during a shuttle walking test vs. a 6-min walking test to assess exercise tolerance in COPD patients. Eur J Appl Physiol 2003;89:331-336.

32 Sun XG, Hansen JE, Oudiz RJ, Wasserman $\mathrm{K}$ : Exercise pathophysiology in patients with primary pulmonary hypertension. Circulation 2001;104:429-435.

33 Agustí AG, Noguera A, Sauleda J, Sala E, Pons J, Busquets X: Systemic effects of chronic obstructive pulmonary disease. Eur Respir J 2003;21:347-360.
4 Gosker HR, Kubat B, Schaart G, van der Vusse GJ, Wouters EF, Schols AM: Myopathological features in skeletal muscle of patients with chronic obstructive pulmonary disease. Eur Respir J 2003;22:280-285.

35 Holverda S, Bogaard HJ, Groepenhoff H, Postmus PE, Boonstra A, Vonk-Noordegraaf A: Cardiopulmonary exercise test characteristics in patients with chronic obstructive pulmonary disease and associated pulmonary hypertension. Respiration 2008;76: 160-167. 